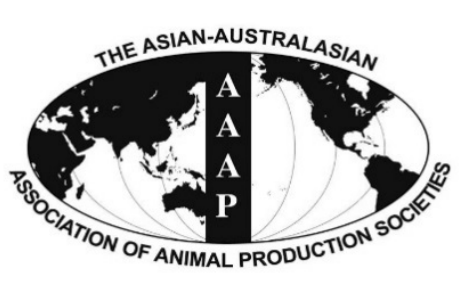

Open Access

Asian Australas. J. Anim. Sci.

Vol. 29, No. 1 : 109-118 January 2016

http://dx.doi.org/10.5713/ajas.15.0253

www.ajas.info

pISSN 1011-2367 elSSN 1976-5517

\title{
Ethanol Extracts from Mistletoe (Viscum album L.) Act as Natural Antioxidants and Antimicrobial Agents in Uncooked Pork Patties during Refrigerated Storage
}

\author{
Suk-Nam Kang* \\ Department of Animal Resource, Daegu University, Gyeongsan 660-758, Korea
}

\begin{abstract}
The antioxidant potential of mistletoe (Viscum album L. var. coloratum Ohwi; VAL) extract in uncooked pork patties was evaluated. Three concentrations of VAL extract (0.1 [T1], 0.5\% [T2] and 1.0\% [T3]) along with $0.02 \%$ ascorbic acid as a positive control $(\mathrm{V})$ were added to ground pork and pork patties were prepared. Incorporation of VAL extract decreased $(\mathrm{p}<0.05)$ the $\mathrm{pH}$ of the pork patties throughout the storage time and reduced $(\mathrm{p}<0.01)$ the thiobarbituric acid reactive substance values after day 14 of storage. Total plate counts of the VAL extract-treated samples and V-treated samples were also significantly lower $(\mathrm{p}<0.01)$ than that of the control (C) throughout the storage period. In addition, odor scores of the VAL extract-treated patties were lower than those of the C- or V-treated samples on 3rd day of the storage period. These results demonstrated that the VAL extract acts as a natural antioxidant in uncooked pork products. (Key Words: Mistletoe Extract, Antioxidant, Lipid Oxidation, Microbial Counts, Uncooked Pork Patties)
\end{abstract}

\section{INTRODUCTION}

Synthetic and natural antioxidants have been successfully utilized to prevent or delay auto-oxidation in meat (McCarthy et al., 2001a). Addition of synthetic antioxidants such as butylated hydroxyanisole (BHA), butylated hydroxytoluene (BHT), and tertiary butylhydroquinone has been reported to be very effective for preventing oxidative changes in meat products (Khalil and Mansour, 1998). However, use of these synthetic antioxidants has been restricted due to possible health risks and toxicity (Buxiang and Fukuhara, 1997). Furthermore, consumers are increasingly demanding additive-free or natural meat products (Ahn et al., 2002). A large number of naturally occurring compounds such as flavonoids, catechins, lignans, and phenolic acids contained in herbs and spices have antioxidant properties. Natural antioxidants have recently become a major area of research. The term 'mistletoe' is generally applied to plants with a similar

* Corresponding Author: Suk-Nam Kang. Tel: +82-55-751-3512, Fax:+82-55-751-3689, E-mail: whitenightt@hanmail.net Submitted Mar. 20, 2015; Revised Jun. 1, 2015; Accepted Jul. 19, 2015 hemiparasitic lifestyle and a certain degree of taxonomical relationship in three families: Loranthaceae, Viscaceae, and Eremolepidaceae (Bar-Sela, 2011). Mistletoe is capable of photosynthesis but relies on xylem sap of host plants to obtain water and mineral nutrients (Ehleringer and Marshall, 1995). It was reported that mistletoe contains lectins (Franz et al., 1981), alkaloids (Khwaja et al., 1980), viscotoxins (Romagnoli et al., 2000), and polysaccharides (Mueller and Anderer, 1990). Clinical and experimental studies showed that extracts from Viscum album L. (VAL), a type of mistletoe that lives on the Quercus acutissima tree, exert cytotoxic effects (Jung et al., 1990) and possess immunostimulatory properties (Mannel et al., 1991). Despite the fact that heat-treated mistletoe extracts are widely consumed as tea or medical reagents, the ability of mistletoe extracts to help preserve meat products is unclear. In the present study, the antioxidant activity of VAL extract in meat was investigated. In addition, the color, total plate count (TPC), coliform, and 2-thiobarbituric acid reactive substances (TBARS) of uncooked pork patties treated with VAL extract were evaluated during a 14-d chilled storage period. 


\section{MATERIALS AND METHODS}

\section{Materials}

Catechin, quercetin, Folin-Ciocalteu reagent, deoxyribose, deoxyribose, xanthine oxidase, hypoxantine, aluminium chloride $\left(\mathrm{AlCl}_{3}\right)$, sodium hydroxide $(\mathrm{NaOH})$, ethylenediaminetetraacetic acid (EDTA), iron chloride $\left(\mathrm{FeCl}_{3}\right)$, L-ascorbic acid, BHA, thiobarbituric acid (TBA), trichloroacetic acid (TCA) and nitroblue tetrazolium (NBT) were purchased from Sigma Chemical Co. (St. Louis, MO, USA). Sodium chloride $(\mathrm{NaCl})$ and sodium nitrite $\left(\mathrm{NaNO}_{2}\right)$ were purchased from Nacalai Tesque Inc. (Kyoto, Japan). Methanol and ethanol used was of HPLC grade and all other solvents used in this study were of analytical grade.

\section{VAL extract preparation}

The stems of $V$. album that lives on the Quercus acutissima tree were purchased from a local market (Sanchung market, Jinju, Republic of Korea). The plant materials were air-dried for $7 \mathrm{~d}$ at room temperature in the dark, and then powdered with a mill (Shinil SFM-555SP, Hwasung, Korea). The dried and powdered plant material $(100 \mathrm{~g})$ was subjected to extraction with $70 \%$ ethanol $(900$ $\mathrm{mL}$ ) at room temperature for $7 \mathrm{~d}$ with occasional stirring. The sample was filtered (Whatman Ltd, Maidstone, Kent, England) and the ethanol was removed (RW-0524G; Heidolph, Germany) at $40^{\circ} \mathrm{C}$. The dried extract was redissolved in water ( $2 \mathrm{~g}$ of extract was first dissolved in a minimum amount of ethanol and then $200 \mathrm{~mL}$ of water were added), dried in a freeze-drier (PVTFD10R, ILSIN Bio Co., Dongduchun, Korea), and stored at $-20^{\circ} \mathrm{C}$ until further use.

\section{Total phenolic contents of VAL extract}

Total phenolic contents of the VAL extracts were determined spectrophotometrically according to the FolinCiocalteu colorimetric method (Singleton and Rossi, 1965). Because catechin a polyphenolic compounds, total phenolic contents of the VAL extract were expressed as $\mu \mathrm{g}$ catechin equivalents (CE)/g extract. Different concentrations of (+)catechin were prepared in $80 \%$ methanol, and absorbance was recorded at $765 \mathrm{~nm}$. For analysis, $100 \mu \mathrm{L}$ of sample (1 $\mathrm{mg} / \mathrm{mL}$ ) was dissolved in $500 \mu \mathrm{L}$ (1:10 dilution) of FolinCiocalteu reagent and $1,000 \mu \mathrm{L}$ of double distilled water (DDW), mixed, and incubated at room temperature for 1 min. Next, $1,500 \mu \mathrm{L}$ of $20 \%$ sodium carbonate $\left(\mathrm{Na}_{2} \mathrm{CO}_{3}\right)$ solution was added. The mixture was shaken and then incubated for $2 \mathrm{~h}$ in the dark at room temperature. Absorbance of all samples was measured using a spectrophotometer (Ultrospec 2100 pro; Amersham Pharmacia Biotech Co., Piscataway, NJ, USA).

\section{Total flavonoid contents of VAL extract}

Total flavonoid contents of the VAL extract were determined using the method described by Meda et al. (2005) with minor modifications. Briefly, $0.25 \mathrm{~mL}$ of sample $(1 \mathrm{mg} / \mathrm{mL})$ was added to a tube containing $1 \mathrm{~mL}$ of DDW. Next, $0.075 \mathrm{~mL}$ of $5 \% \mathrm{NaNO}_{2}, 0.075 \mathrm{~mL}$ of $10 \%$ $\mathrm{AlCl}_{3}$, and $0.5 \mathrm{~mL}$ of $1 \mathrm{M} \mathrm{NaOH}$ were sequentially added at 0,5 , and 6 min. Finally, the volume of the solution was adjusted to $2.5 \mathrm{~mL}$ with DDW. Absorbance of the solution was measured at a wavelength of $410 \mathrm{~nm}$ with a spectrophotometer (Ultrospec 2100 pro, Amersham Pharmacia Biotech Co., USA). Quercetin, a ubiquitous flavonoid present in many plant extracts, was used as a standard to quantify the total flavonoid contents of the VAL extract. The results are expressed as $\mu \mathrm{g}$ quercetin equivalents $(\mathrm{QE}) / \mathrm{g}$ of extract. The total flavonoid content was measured five times and the experiment was repeated three times.

\section{Free radical scavenging activity of VAL extract}

Free radical scavenging activity (FRSA) of the VAL extract $(1 \mathrm{mg} / \mathrm{mL})$ was measured using the method described by Brand-Williams et al. (1995). Briefly, a 100 $\mathrm{mL}$ solution of VAL extract $(1 \mathrm{mg} / \mathrm{mL})$ in ethanol was mixed with $100 \mu \mathrm{L}$ of $0.1 \mathrm{mM}$ 2,2-diphenyl-1-picrylhydrazyl-hydrate (DPPH) in ethanol. The mixtures were shaken vigorously and allowed to stand at room temperature in the dark for $25 \mathrm{~min}$. Thereafter, the absorbance of the assay mixture was measured at $518 \mathrm{~nm}$ against each blank in a spectrophotometer (Ultrospec 2100 pro; Amersham Pharmacia Biotech Co., USA). L-ascorbic acid was used as a positive control. The percent inhibition was calculated using the following equation:

$$
\begin{aligned}
& \text { Inhibition } \% \\
& =[(\text { absorbance of control }- \text { absorbance of sample }) / \\
& \quad \text { absorbance of control }] \times 100
\end{aligned}
$$

\section{Hydroxyl radical scavenging activity of VAL extract}

Hydroxyl radical scavenging activity (HRSA) of the VAL extract was measured using the deoxyribose method (Halliwell, 1996) with a slight modification. The assay was performed with $10 \mathrm{mM}$ phosphate buffer $(\mathrm{pH}$ 7.4) containing $2.5 \mathrm{mM}$ deoxyribose, $1.5 \mathrm{mM} \mathrm{H}_{2} \mathrm{O}_{2}, 100 \mu \mathrm{M}$ $\mathrm{FeCl}_{3}, 104 \mu \mathrm{M}$ EDTA, and the test sample $(0.5 \mathrm{mg} / \mathrm{mL})$. The reaction was initiated by adding ascorbic acid at a final concentration of $100 \mu \mathrm{M}$. The reaction mixture was then incubated for $1 \mathrm{~h}$ at $37^{\circ} \mathrm{C}$ in a water bath. After incubation, color was developed by the addition of $0.5 \%$ TBA followed by ice-cold $2.8 \%$ TCA in $25 \mathrm{mM} \mathrm{NaOH}$ and heating for 30 min at $80^{\circ} \mathrm{C}$. A sample of the extract without any additions was used as the control (A1). Sample A2 was cooled on ice and the absorbance was measured at $532 \mathrm{~nm}$. The HRSA 
was calculated as follows:

$$
\operatorname{HRSA} \%=(\mathrm{A} 1-\mathrm{A} 2 / \mathrm{A} 1) \times 100
$$

\section{Superoxide anion radical scavenging activity of VAL extract}

Superoxide anion radicals were generated using a modified method by Liu et al. (1997). VAL extract samples $(0.5 \mathrm{mg} / \mathrm{mL}$ in dimethyl sulfoxide were added to a reaction solution containing $100 \mu \mathrm{L}$ of $30 \mathrm{mM}$ EDTA (pH 7.4), 10 $\mu \mathrm{L}$ of $30 \mathrm{mM}$ hypoxantine in $50 \mathrm{mM} \mathrm{NaOH}$, and $200 \mu \mathrm{L}$ of $1.42 \mathrm{mM}$ NBT; mixed, and preincubated at room temperature for $3 \mathrm{~min}$. Next, $100 \mu \mathrm{L}$ of $0.5 \mathrm{U} / \mathrm{mL}$ xanthine oxidase was added to the mixture and the volume was brought up to $3 \mathrm{~mL}$ with $50 \mathrm{mM}$ phosphate buffer ( $\mathrm{pH}$ 7.4). The solution was then incubated at room temperature for 20 min and absorbance was measured at $560 \mathrm{~nm}$. A sample of reaction mixture without xanthine oxidase was used as a blank (A1). VAL extract (A2) was added to the reaction mixture, and superoxide anion radical scavenging was measured by assessing the inhibition of NBT reduction. Absorbance was measured and decreases in superoxide anions were calculated as follows:

Superoxide anion radical scavenging activity (SRSA \%) $=(\mathrm{A} 2-\mathrm{A} 1 / \mathrm{A} 1) \times 100$

\section{Preparation of fresh minced pork}

Pork (longissimus dori) and back-fat were obtained from a meat processing company (Asian C\&A Co. Ltd., Jinju, Korea) and chilled overnight at $4{ }^{\circ} \mathrm{C}$. Meat and backfat were separately minced twice (with a $10-\mathrm{mm}$ steel plate followed by $5-\mathrm{mm}$ steel plate) in a mincer (model MGB-32; Fugee, Uijeongbu, Korea). The minced meat (85\%) was thoroughly mixed with back-fat $(15 \%)$ and refined wheat flour (3\%) in a silent cutter (AS-30; Ramon Co., Oiartzum, Spain). The minced meat was then divided into five aliquots: control sample (no functional ingredients were added, $\mathrm{C}$ ), minced meat mixed with $0.02 \%$ ascorbic acid $(\mathrm{V})$; and minced meat mixed with $0.1 \%$ (T1), $0.5 \%$ (T2), or $1.0 \%$ (T3) of dry VAL extract powder (dry base, w/w). The concentrations of VAL extract were selected mainly based on preliminary studies of sensory evaluation. The dry VAL ethanol extract was dissolved in DDW $(10 \%$, v/w), added immediately to the minced pork samples, and mixed thoroughly. The same volume of DDW was added to the control minced pork sample. Portions of the treated minced pork (50 g) were formed into patties (model K450; Ningbo Heng Yue Plastic Factory, Yuyao, China), placed in laminated low oxygen-permeable packs $\left(0.5 \mathrm{~cm}^{3} / \mathrm{m}^{2} / \mathrm{atm} / 24\right.$ h; Danisco Flexible, Lyngby, Denmark), and then stored up to $14 \mathrm{~d}$ at $4^{\circ} \mathrm{C}\left( \pm 1^{\circ} \mathrm{C}\right)$ before subsequent analysis. The experiment was repeated in triplicate with three observations per replication. The manufacturing process was repeated four times; thus, 20 batches of patties were produced.

\section{Color evaluation of the pork patties}

Color of the VAL-treated meat was measured with a spectrocolourimeter (CR 400; Minolta Co., Osaka, Japan) calibrated using a white plate and light trap supplied by the manufacturer. Color was expressed based on the Commission Internationale de l'Eclairage $\mathrm{L} * \mathrm{a} * \mathrm{~b} *$ color system in which $\mathrm{L}^{*}$ is lightness, $\mathrm{a}^{*}$ redness, and $\mathrm{b}^{*}$ yellowness. Measurements were made using the $\mathrm{C}$ illuminant and $2^{\circ}$ standard observers. A total of six spectral readings were taken for each VAL-treated meat sample with different instrument orientations, and measurements were recorded on days 1, 3, 7, and 14 for all vacuum-packed samples. Each color parameter was evaluated in triplicate and the experiment was repeated three times.

\section{Lipid oxidation of the pork patties}

A 2-TBARS test was performed according to Tarladgis et al. (1960) to measure oxidative rancidity. A sample of VAL-treated meat $(5 \mathrm{~g})$ was homogenized with $2.5 \mu \mathrm{L}$ of BHA $(7.2 \%$ in ethanol) and $15 \mathrm{~mL}$ of DDW using a homogenizer (IKA model T-25 Basic, Selangor, Malaysia). Two $\mathrm{mL}$ of the homogenate were mixed with $4 \mathrm{~mL}$ of TBA in a TCA solution ( $20 \mathrm{mM}$ TBA in $15 \%$ TCA), heated at $90^{\circ} \mathrm{C}$ for $15 \mathrm{~min}$ in a water bath, cooled on ice, and centrifuged 2,000 rpm for $15 \mathrm{~min}$ at $4{ }^{\circ} \mathrm{C}$ (UNION 5KR; Hanil Science Industrial, Co., Ltd., Incheon, Korea). Absorbance of the supernatant was measured at $532 \mathrm{~nm}$ in a spectrophotometer (Spectronic model Genesys-5, San Francisco, CA, USA). The malonaldehyde concentration $(\mathrm{mg} / \mathrm{kg})$ was calculated based on a standard curve. TBARS values were measured on days $1,3,7$, and 14 for all vacuum-packed samples. The TBARS values were measured in triplicate and the experiment was repeated three times.

\section{Microbial analysis of the pork patties}

Samples of VAL-treated meat (25 g) were taken aseptically, transferred to sterile plastic pouches (Seward, London, UK), and homogenized for $2 \mathrm{~min}$ at room temperature in $225 \mathrm{~mL}$ sterile $0.88 \%(\mathrm{w} / \mathrm{v}) \mathrm{NaCl}$ solution in a stomacher Lab-Blender 78860 (ST-Nom; Interscience, St. Nam, France). Appropriate dilutions of the samples were prepared in sterile $0.88 \%(\mathrm{w} / \mathrm{v}) \mathrm{NaCl}$ solution, plated in duplicate onto plate count agar (Difco Laboratory, Detroit, MI, USA), and incubated at $35^{\circ} \mathrm{C}$ for $48 \mathrm{~h}$ under aerobic conditions. Results are expressed as $\log _{10}$ colony forming units (CFU)/g VAL-treated pork after 1, 3, 7, and $14 \mathrm{~d}$ of 
storage. Each microbial count was performed in triplicate and the experiment was repeated three times.

\section{Sensory evaluation of the pork patties}

On day 3 of storage, the pork patties were analyzed by 12 experienced panel members. Twelve training sessions were held to familiarize the panelists with the attributes to be evaluated and the assessment scale. The samples were cut into pieces of $2.0 \times 3.0 \times 2.0 \mathrm{~cm}^{3}$ and served to each panelist separately under white illumination. The panelists were presented randomly coded samples. The color, aroma, and flavor $(1=$ extremely undesirable, $9=$ extremely desirable), off-odor ( $1=$ low intensity, $9=$ very high intensity), and overall acceptability $(1=$ extremely undesirable, 9 = extremely desirable) of the samples were evaluated. The panelists were required to cleanse their palates with water between samples. Sensory evaluation was performed three times.

\section{Statistical analysis}

Data were analyzed using the general linear model of the Statistical Analysis System's Procedures (SAS Institute Inc., 1999). Duncan's multiple range tests were used to identify differences between mean values. Significance was set at $5 \%$.

\section{RESULTS AND DISCUSSION}

\section{Total phenolic contents of VAL extract}

Phenolic compounds, such as quercetin, rutin, narigin, catechins, caffeic acid, gallic acid, and chlorogenic acid, are very important plant constituents due to their antioxidant activities (Paganga et al., 1999). The total phenolic contents of the VAL extract are presented as $(+)-\mathrm{CE}$ in Table 1. Results revealed that the total phenolic content was 60.46 $\mathrm{mg} / \mathrm{g}$ dry weight. Varela et al. (2004) reported that the methanol extract of Phoradendron liga (Gill. ex H. et A.) Eichl. (Viscaceae) leaves is $29.6 \pm 4.2 \mathrm{mg} / \mathrm{g}$ dry weight and that of stems is $19.6 \pm 7.0 \mathrm{mg} / \mathrm{g}$ dry weight when expressed as tannin acid equivalents. The quantity of total phenolic contents was reported to be affected by molecular weight of the standard used such as catechin and gallic acid (290.27 and 170.12, respectively) for the same sample (Chen and Yen, 2007). The levels of total phenolic compounds in the VAL extract presented as (+)-CE were similar to those reported by Varela et al. (2004) who used gallic acid as a standard.

\section{Flavonoid content of VAL extract}

Flavonoids are ubiquitous in plants and form a group of low molecular weight polyphenolic compounds. Antioxidant activity and capacity to inhibit the growth of cancer cells are among the important effects of these reagents in biological systems (Zolezzi et al., 2005). The stems and leaves of Argentine mistletoe (Ligaria cuneifolia [R. et P.] Tiegh. [Loranthaceae]) were reported to contain quercetin as the only flavonol, which was also found to occur freely and only monoglycosylated with xylose, rhamnose, and arabinose at the hydroxyl group in position 3 of the flavonol skeleton (Fernández et al., 1998). The concentration of flavonoids in the VAL extract was 36.38 $\mathrm{mg} \mathrm{QE} / \mathrm{g}$ dry weight as detected by $2 \%$ aluminum chloride (Table 1).

\section{FRSA of VAL extract}

The DPPH is a stable free radical. Researchers have used this compound to evaluate the efficiency of antioxidants and flavonoids (Brand-Williams et al., 1995). The DPPH radical has been widely used to measure the FRSA of various natural products and is accepted as a model compound of free radicals originating from lipids (Da Porto et al., 2000). Results of the FRSA analysis for the VAL extract are shown in Table 1. For this experiment, BHA and ascorbic acid served as references. The FRSA of BHA was $81.38 \%$ and $64.11 \%$ for ascorbic acid at equal concentrations $(1 \mathrm{mg} / \mathrm{mL})$. The VAL extract generally showed a high antioxidant capacity and significant $(\mathrm{p}<0.05)$ differences between samples were observed at the same concentration $(1 \mathrm{mg} / \mathrm{mL})$. These results clearly indicated that all tested samples exhibited different levels of antioxidant activity $(\mathrm{p}<0.05)$ in the following order: ascorbic acid $>$ BHA $>$ VAL extracts $(34.01 \%)$.

Table 1. Total phenolic and flavonoid contents along with antioxidant activities of the mistletoe (Viscum album L.; VAL) ethanol extract

\begin{tabular}{llccc}
\hline & VAL extract & BHA & Ascorbic acid & Quercetin \\
\hline Total phenolic contents $(\mathrm{mg} \mathrm{CE} / \mathrm{g})$ & $60.46 \pm 3.38$ & & & \\
Total flavonoid contents (mg QE/g) & $36.38 \pm 1.89$ & & & - \\
FRSA $(1 \mathrm{mg} / \mathrm{mL})$ & $34.01 \pm 2.68^{\mathrm{c}}$ & $64.11 \pm 1.23^{\mathrm{b}}$ & $81.38 \pm 2.25^{\mathrm{a}}$ & - \\
HRSA $(1 \mathrm{mg} / \mathrm{mL})$ & $40.19 \pm 1.61^{\mathrm{b}}$ & $47.58 \pm 2.28^{\mathrm{a}}$ & $35.51 \pm 1.90^{\mathrm{b}}$ & - \\
SRSA $(0.5 \mathrm{mg} / \mathrm{mL})$ & $30.05 \pm 4.11^{\mathrm{b}}$ & - & - & $73.98 \pm 0.75^{\mathrm{a}}$ \\
\hline
\end{tabular}
$\mathrm{n}=5$.

BHA, butylated hydroxyanisole; CE, catechin equivalents; QE, quercetin equalents; FRSA, free radical scavenging activity; HRSA, hydroxyl radical scavenging activity; SRSA, superoxide anion radical scavenging activity.

${ }^{\mathrm{a}-\mathrm{c}}$ Different letters in the same row indicate that mean values \pm standard deviation (SD) were significantly different ( $\mathrm{p}<0.01$ ). 


\section{HRSA of VAL extract}

Among the reactive oxygen species, hydroxyl radicals are the most reactive and predominant radicals generated endogenously during aerobic metabolism that inflict cell damage in vivo (Mates and Sanchez-Jimenez, 2000). Inhibition of deoxyribose degradation is considered an indication of hydroxyl radical scavenging action (Halliwell et al., 1987; Lopes et al., 1999). The HRSA of VAL extracts at a concentration of $0.5 \mathrm{mg} / \mathrm{mL}$ relative to the same concentration of BHA and ascorbic acid is shown in Table 1. For this experiment, BHA and ascorbic acid were used as references. The HRSA was $47.58 \%$ for BHA and $35.51 \%$ for ascorbic acid at the same concentration $(1 \mathrm{mg} / \mathrm{mL})$. Significantly higher HRSA for BHA was observed. The HRSA of the VAL extract was similar to that of ascorbic acid.

\section{SRSA of VAL extract}

Superoxide anions are a reduced form of molecular oxygen created by the addition of one electron. Superoxide radicals have been observed to kill cells, inactivate enzymes; and degrade DNA, cell membranes, and polysaccharides (Halliwell, 1996). FRSA was, therefore, proposed to measure the comparative interceptive ability of antioxidant extracts to scavenge the superoxide radical (Vani et al., 1997). The SRSA of the VAL extract was compared to that of quercetin $(0.5 \mathrm{mg} / \mathrm{mL})$ at the same concentration as shown in Table 1. The SRSA of the VAL extract was lower than that of quercetin $(73.98 \% ; \mathrm{p}<0.05)$. These data indicated that the VAL extract is a relatively good source of antioxidants in terms of phenolic and flavonoid contents. Thus, the effect of the extract on the quality of pork patties was evaluated.

\section{pH of pork patties}

In Table 2, $\mathrm{pH}$ of the uncooked pork patties mixed with the VAL extract and refrigerated is presented. The $\mathrm{pH}$ values significantly decreased $(\mathrm{p}<0.01)$ from day 1 to day 14 of storage for all samples, but this change was more drastic for the control. On the first day of storage, $\mathrm{pH}$ values
Table 2. Changes in $\mathrm{pH}$ of fresh pork patties mixed with Viscum album L. (VAL) extract

\begin{tabular}{lcccc}
\hline \multirow{2}{*}{ Treatment } & \multicolumn{4}{c}{ Storage period (d) } \\
\cline { 2 - 5 } & 1 & 3 & 7 & 14 \\
\hline $\mathrm{C}$ & $5.75 \pm 0.09^{\mathrm{Aa}}$ & $5.81 \pm 0.04^{\mathrm{A}}$ & $5.47 \pm 0.10^{\mathrm{B}}$ & $5.44 \pm 0.06^{\mathrm{Aa}}$ \\
$\mathrm{V}$ & $5.61 \pm 0.03^{\mathrm{Abc}}$ & $5.65 \pm 0.06^{\mathrm{A}}$ & $5.43 \pm 0.02^{\mathrm{A}}$ & $4.75 \pm 0.02^{\mathrm{Bb}}$ \\
$\mathrm{T} 1$ & $5.65 \pm 0.01^{\mathrm{Ab}}$ & $5.69 \pm 0.06^{\mathrm{A}}$ & $5.43 \pm 0.06^{\mathrm{B}}$ & $4.78 \pm 0.02^{\mathrm{Cb}}$ \\
$\mathrm{T} 2$ & $5.54 \pm 0.03^{\mathrm{Bd}}$ & $5.64 \pm 0.07^{\mathrm{A}}$ & $5.44 \pm 0.06^{\mathrm{C}}$ & $4.75 \pm 0.07^{\mathrm{Db}}$ \\
$\mathrm{T} 3$ & $5.56 \pm 0.04^{\mathrm{Acd}}$ & $5.62 \pm 0.02^{\mathrm{A}}$ & $5.41 \pm 0.03^{\mathrm{A}}$ & $4.65 \pm 0.04^{\mathrm{Bc}}$ \\
\hline
\end{tabular}

Values represent the mean of triplicate measurements.

${ }^{1} \mathrm{C}$, uncooked pork patty without any added functional ingredients; V, uncooked pork patty mixed with $0.02 \%$ ascorbic acid; T1, T2, and T3, fresh patties mixed with $0.1 \%, 0.5 \%$, and $1.0 \%$ VAL extract, respectively (dry base, w/w).

${ }^{A-C}$ Mean values \pm standard deviation with different letters in the same row are significantly different $(\mathrm{p}<0.01)$.

${ }^{\text {a-d }}$ Mean values \pm standard deviation with different letters in the same column are significantly different $(\mathrm{p}<0.01)$.

of the VAL-treated patties were lower than those of the control $(\mathrm{p}<0.01)$. This could be due to the low $\mathrm{pH}$ of the VAL extract itself (3.63). The $\mathrm{pH}$ values measured on the third and seventh day of storage were not significantly $(p>0.05)$ different when comparing the control and VALtreated patties. However, the $\mathrm{pH}$ values of the VAL-treated patties were lower than those of the control $(p<0.01)$ on the 14 th day of storage. This difference could be attributed to the greater aerobic bacterial multiplication in the control compared to the VAL-treated samples (Table 3). These results were in agreement with data produced by Ahn et al. (2004) for ground beef and Juntachote et al. (2007) for ground pork.

\section{Color analysis of pork patties}

Color plays an important role in both the quality and consumer acceptance of pork. Changes in color values of the uncooked pork patties mixed with VAL extract are presented in Table 4. On the first day of storage, the control exhibited the highest color value ( $\mathrm{L}^{*}$ value or lightness). Lightness was significantly different $(p<0.05)$ among all samples on different storage days. This was clearly observed for the control in which lightness significantly

Table 3. Changes in total plate counts (TPCs) expressed as log CFU/g of uncooked pork patties mixed with VAL ethanol extract

\begin{tabular}{lcccc}
\hline Treatments $^{1}$ & \multicolumn{4}{c}{ Storage period (d) } \\
\cline { 2 - 5 } & 1 & 3 & 7 & 14 \\
\hline $\mathrm{C}$ & $4.19 \pm 0.66^{\mathrm{Ca}}$ & $5.29 \pm 0.07^{\mathrm{Ba}}$ & $5.98 \pm 0.27^{\mathrm{Aa}}$ & $6.51 \pm 0.33^{\mathrm{Aa}}$ \\
$\mathrm{V}$ & $3.04 \pm 0.21^{\mathrm{Bb}}$ & $3.06 \pm 0.34^{\mathrm{Bb}}$ & $5.03 \pm 0.23^{\mathrm{Ab}}$ & $5.27 \pm 0.41^{\mathrm{Abc}}$ \\
$\mathrm{T} 1$ & $2.73 \pm 0.12^{\mathrm{Cb}}$ & $2.37 \pm 0.04^{\mathrm{Cc}}$ & $4.45 \pm 0.38^{\mathrm{Bc}}$ & $5.67 \pm 0.40^{\mathrm{Ab}}$ \\
$\mathrm{T} 2$ & $2.73 \pm 0.55^{\mathrm{Bb}}$ & $2.58 \pm 0.34^{\mathrm{Bc}}$ & $4.84 \pm 0.43^{\mathrm{Abc}}$ & $5.04 \pm 0.24^{\mathrm{Ac}}$ \\
$\mathrm{T} 3$ & $2.83 \pm 0.26^{\mathrm{Bb}}$ & $2.67 \pm 0.04^{\mathrm{Bbc}}$ & $4.71 \pm 0.18^{\mathrm{Abc}}$ & $5.06 \pm 0.18^{\mathrm{Ac}}$ \\
\hline
\end{tabular}

Values represent the mean of triplicate measurements.

CFU, colony-forming unit; VAL, Viscum album L.; SD, standard deviation.

${ }^{1} \mathrm{C}$, uncooked pork patty without any added functional ingredients; $\mathrm{V}$, uncooked pork patty mixed with $0.02 \%$ ascorbic acid; $\mathrm{T} 1$, T2, and T3, fresh patties mixed with $0.1 \%, 0.5 \%$, and $1.0 \%$ VAL extract, respectively (dry base, $\mathrm{w} / \mathrm{w}$ ).

${ }^{A-C}$ Mean values \pm SD with different letters in the same row are significantly different $(\mathrm{p}<0.01)$.

${ }^{a-b}$ Mean values \pm SD with different letters in the same column are significantly different $(\mathrm{p}<0.01)$. 
Table 4. Changes in the color of uncooked pork patties mixed with VAL ethanol extract

\begin{tabular}{|c|c|c|c|c|c|c|}
\hline \multirow{2}{*}{ Index } & \multirow{2}{*}{ Treatments $^{1}$} & \multicolumn{4}{|c|}{ Storage period $(\mathrm{d})$} & \multirow{2}{*}{ p-value } \\
\hline & & 1 & 3 & 7 & 14 & \\
\hline \multirow[t]{6}{*}{$\mathrm{L}^{*}$} & $\mathrm{C}$ & $65.83 \pm 0.91^{\mathrm{Aa}}$ & $66.00 \pm 1.35^{\mathrm{Aa}}$ & $65.87 \pm 1.76^{\mathrm{Aa}}$ & $62.30 \pm 0.78^{\mathrm{Bb}}$ & $*$ \\
\hline & $\mathrm{V}$ & $64.07 \pm 0.59^{\mathrm{abc}}$ & $66.70 \pm 2.76^{\mathrm{a}}$ & $65.53 \pm 1.34^{\mathrm{ab}}$ & $68.00 \pm 1.31^{\mathrm{a}}$ & \\
\hline & $\mathrm{T} 1$ & $65.00 \pm 1.32^{\mathrm{Bab}}$ & $63.50 \pm 1.70^{\mathrm{Bab}}$ & $65.63 \pm 0.40^{\mathrm{Bab}}$ & $68.57 \pm 1.80^{\mathrm{Aa}}$ & $* *$ \\
\hline & $\mathrm{T} 2$ & $63.10 \pm 0.92^{\mathrm{Bbc}}$ & $62.03 \pm 0.64^{\mathrm{Bb}}$ & $63.03 \pm 2.12^{\mathrm{Bbc}}$ & $69.53 \pm 1.75^{\mathrm{Aa}}$ & $* *$ \\
\hline & $\mathrm{T} 3$ & $62.43 \pm 1.65^{\mathrm{c}}$ & $61.60 \pm 1.37^{\mathrm{b}}$ & $62.67 \pm 0.91^{\mathrm{c}}$ & $63.50 \pm 1.47^{\mathrm{b}}$ & \\
\hline & p-value & $*$ & $* *$ & $*$ & $* *$ & \\
\hline \multirow[t]{6}{*}{$a^{*}$} & $\mathrm{C}$ & $6.40 \pm 1.01^{\mathrm{AB}}$ & $7.30 \pm 0.53^{\mathrm{A}}$ & $7.04 \pm 0.69^{\mathrm{A}}$ & $5.54 \pm 0.31^{\mathrm{B}}$ & $*$ \\
\hline & V & $7.73 \pm 0.31^{\mathrm{A}}$ & $6.73 \pm 1.03^{\mathrm{AB}}$ & $7.00 \pm 0.79^{\mathrm{A}}$ & $5.50 \pm 0.40^{\mathrm{B}}$ & $*$ \\
\hline & $\mathrm{T} 1$ & $7.73 \pm 0.90^{\mathrm{A}}$ & $8.23 \pm 0.64^{\mathrm{A}}$ & $7.60 \pm 0.30^{\mathrm{A}}$ & $4.57 \pm 0.46^{\mathrm{B}}$ & $* *$ \\
\hline & $\mathrm{T} 2$ & $7.70 \pm 1.04^{\mathrm{A}}$ & $7.77 \pm 0.29^{\mathrm{A}}$ & $7.93 \pm 0.47^{\mathrm{A}}$ & $4.43 \pm 0.58^{\mathrm{B}}$ & $* *$ \\
\hline & $\mathrm{T} 3$ & $6.80 \pm 0.78^{\mathrm{A}}$ & $6.90 \pm 0.56^{\mathrm{A}}$ & $6.43 \pm 0.75^{\mathrm{A}}$ & $4.63 \pm 0.80^{\mathrm{B}}$ & $*$ \\
\hline & p-value & & & & & \\
\hline \multirow[t]{6}{*}{$b^{*}$} & $\mathrm{C}$ & $13.03 \pm 1.02^{\mathrm{Ab}}$ & $12.97 \pm 0.21^{\mathrm{Ac}}$ & $12.47 \pm 0.61^{\mathrm{ABbc}}$ & $11.20 \pm 1.11^{\mathrm{Bc}}$ & $*$ \\
\hline & $\mathrm{V}$ & $13.37 \pm 0.06^{\mathrm{b}}$ & $13.50 \pm 0.72^{\mathrm{bc}}$ & $13.01 \pm 0.40^{\mathrm{c}}$ & $13.10 \pm 0.10^{\mathrm{b}}$ & \\
\hline & $\mathrm{T} 1$ & $13.33 \pm 1.00^{\mathrm{b}}$ & $13.57 \pm 0.29^{b c}$ & $13.40 \pm 0.60^{\mathrm{b}}$ & $12.20 \pm 0.92^{\mathrm{bc}}$ & \\
\hline & $\mathrm{T} 2$ & $14.27 \pm 1.62^{\mathrm{b}}$ & $14.70 \pm 0.40^{\mathrm{ab}}$ & $15.07 \pm 0.45^{\mathrm{a}}$ & $13.40 \pm 0.75^{\mathrm{b}}$ & \\
\hline & $\mathrm{T} 3$ & $16.03 \pm 0.15^{\mathrm{a}}$ & $15.37 \pm 1.10^{\mathrm{a}}$ & $14.67 \pm 0.60^{\mathrm{a}}$ & $14.77 \pm 0.15^{\mathrm{Aa}}$ & \\
\hline & p-value & $*$ & $* *$ & $* *$ & $* *$ & \\
\hline
\end{tabular}

Values represent the mean of triplicate measurements.

VAL, Viscum album L.; SD, standard deviation.

${ }^{1} \mathrm{C}$, uncooked pork patty without any added functional ingredients; $\mathrm{V}$, uncooked pork patty mixed with $0.02 \%$ ascorbic acid; $\mathrm{T} 1$, T2, and T3, fresh patties mixed with $0.1 \%, 0.5 \%$, and $1.0 \%$ VAL extract, respectively (dry base, $\mathrm{w} / \mathrm{w}$ ).

${ }^{A-C}$ Mean values $\pm S D$ with different letters in the same row are significantly different $(* p<0.05$ and $* * p<0.01)$.

${ }^{a-d}$ Mean values \pm SD with different letters in the same column are significantly different $\left({ }^{*} p<0.05\right.$ and $\left.{ }^{* *} p<0.01\right)$.

decreased $(\mathrm{p}<0.05)$ after $14 \mathrm{~d}$ while at the same time lightness of samples $\mathrm{T} 1$ and $\mathrm{T} 2$ was significantly increased $(p<0.05)$. Overall, lightness of the VAL extract-treated pork, except for sample $\mathrm{T} 3$, significantly increased $(\mathrm{p}<0.01)$ after $14 \mathrm{~d}$ of storage compared to the control. The $\mathrm{L}^{*}$ value of raw pork treated with grape seed and bearberry extracts was found to not change over a 12-d period of storage (Carpenter et al., 2007). In contrast, a reduction in the $\mathrm{L}^{*}$ value of chicken patties mixed with natural antioxidants was previously reported (Devatkal et al., 2010).

The intensity and stability of meat color are important attributes to consumers with a preference for pork with more intense pink pigmentation (Brewer et al., 1998). The $\mathrm{a}^{*}$ value (redness) is the most important color parameter for evaluating meat oxidation since decreased redness is associated with reduced consumer acceptance (Renerre, 2000). During storage, significant differences were found in the redness ( $\mathrm{a}^{*}$ values) between the control and VAL extract-treated pork although no significant differences were observed between any tested samples. Samples T1 and T2 had comparatively higher redness scores compared to the control on days 1,3 , and 7 of storage, but these values were not significantly different. By day 14 of storage, redness of all test samples had significantly decreased $(p<0.05)$. These results agree with findings previously reported for other plant extracts of commercial origin
(McCarthy et al., 2001b; Mason et al., 2005).

After day 1 of storage, T3 samples exhibited the highest $\mathrm{b}^{*}$ value (yellowness), while samples T2 and T3 had significantly higher $(p<0.01)$ yellowness compared to the control on days 3,7 , and 14 of storage. Yellowness of the control decreased significantly $(p<0.05)$ after $14 \mathrm{~d}$, but those of the VAL extract-treated samples were not significantly altered throughout the storage period. These results agreed with findings from a study by Biswas et al. (2012) who reported reduced $L^{*}$ values and increased $b^{*}$ values for raw ground pork mixed with natural antioxidants and refrigerated.

\section{TBARS values of pork patties}

In Figure 1, TBARS values of the refrigerated uncooked pork patties mixed with VAL extract are presented. As expected, the TBARS values of the control were significantly increased $(p<0.01)$ between days 1 and 14 of storage, but those of T2 and T3 were significantly decreased during the same storage period. In contrast, the TBARS values of pork treated with $0.02 \%$ ascorbic acid $(\mathrm{V})$ did not significantly changed throughout the storage period. In general, treatment with VAL extract (samples T1, T2, and T3) resulted in lower $(\mathrm{p}<0.05)$ TBARS values compared to the control and V samples on days 7 and 14 of storage. However, TBARS values of the samples treated with the 


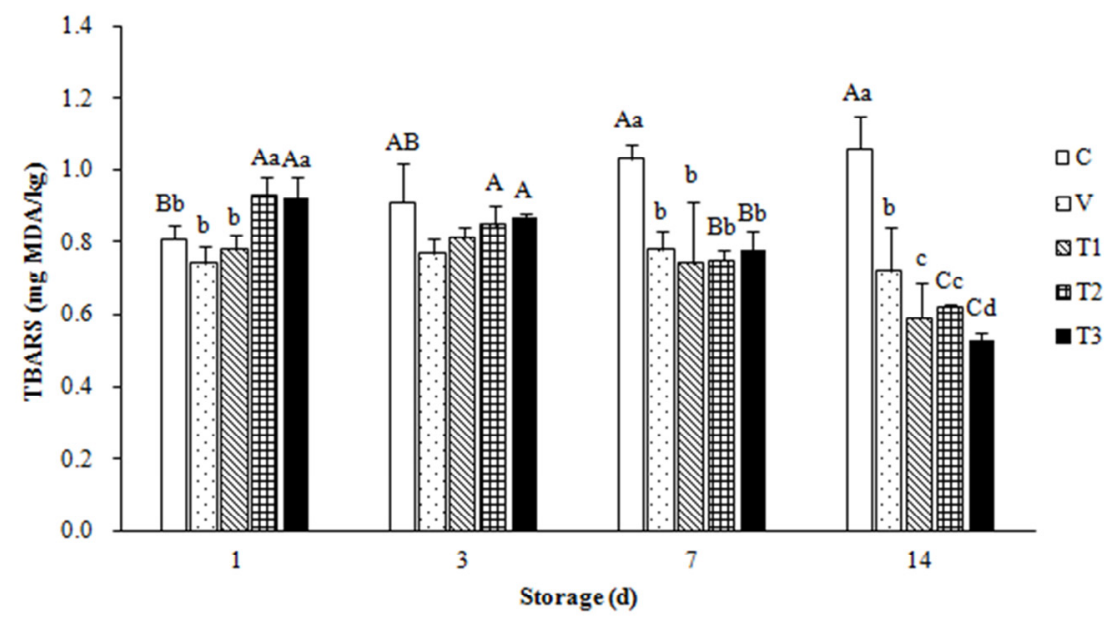

Figure 1. Thiobarbituric acid reactive substance (TBARS) values of fresh minced pork mixed with Viscum album L. (VAL) extract and subjected to refrigerated storage as described in Table 2. Values represent the mean of triplicate determinations. ${ }^{\mathrm{A}-\mathrm{C}}$ Mean values \pm standard deviation (SD) with different letters for the same treatment during different storage periods are significantly different $(\mathrm{p}<0.01)$. ${ }^{\text {a-d }}$ Mean values \pm SD with different letters for different treatments during the same storage period are significantly different $(\mathrm{p}<0.01)$.

$0.5 \%$ and $1.0 \%$ of the VAL extract (T2 and T3) were higher after $1 \mathrm{~d}$ of storage at $4^{\circ} \mathrm{C}$ compared to the other patties.

The TBARS method has been widely used to determine the degree of lipid oxidation. TBARS are produced through the second stage of auto-oxidation during which peroxides are oxidized into aldehydes and ketones (e.g., malondialdehyde). High TBARS values of the T2 and T3 samples observed between the first and third day of storage could be a result of the dark brown pigments of the VAL extract. Ganhão et al. (2011) reported that unexpectedly high TBARS values could be ascribed to the presence of interfering compounds (mainly colored pigments of the tested extracts). Additionally, anthocyanins and other natural pigments that naturally produce red pigmentation similar to that of TBA-malondialdehyde (MDA) adduct should be considered responsible for lipid oxidation.

Numerous plant tissues contain endogenous pigments that absorb the $532 \mathrm{~nm}$ region of the spectrum or form such pigments under acidic conditions, and are necessary for MDA extraction and subsequent reaction with TBA (Draper et al., 1993). However, TBARS values of the VAL extracttreated uncooked pork patties were decreased by $19.03 \%$ and $33.37 \%$ for $\mathrm{T} 2$ and $14.81 \%$ and $42.45 \%$ for T3 after 7 and $14 \mathrm{~d}$ of storage, respectively. Recently, a positive correlation between the phenolic content of plant byproduct extract and reduction of TBARS in cooked goat meat patties was reported (Devatkal et al., 2010). Phenolic compounds are known to inhibit free radical formation and the propagation of free radical reactions through chelation of transition metal ions such as iron (McBride et al., 2007). The antioxidant activity of phenolic compounds was reported to be associated with the hydroxyl group linked to the aromatic ring, which is capable of donating hydrogen atoms with electrons and neutralizing free radicals (Kim et al., 2013). This mechanism blocks further degradation into more active oxidizing forms such as MDA (Oliveira et al., 2012).

\section{TPC of pork patties}

Changes in the TPC of fresh pork patties mixed with the VAL extract and stored at $4^{\circ} \mathrm{C}$ are shown in Table 3 . The relatively high initial TPC of fresh minced pork could be attributed to the mincing process itself, which contributes to increased total viable counts. Significant differences $(p<0.01)$ in the mean TPC were observed between the control and VAL extract-treated pork patties during the entire storage period. TPC of the control increased significantly $(\mathrm{p}<0.01)$ throughout the storage period and reached an unacceptable level (almost $6 \mathrm{CFU} / \mathrm{g}$ ) on day 14 . On day 3, the TPCs all VAL extract-treated samples showed more than $2 \log$ reductions compared to the control. The TPCs of V, T1, T2, and T3 samples were reduced by approximately $1.3 \log$ on days 1,7 , and 14 compared to the control. The VAL extract reduced the TPC $(p<0.01)$ throughout the storage period relative to the control values. A concentration of $0.1 \%$ VAL extract was sufficient while a dose of $1.0 \%$ provided no significant improvement. Thus, the addition of $0.1 \%$ VAL extract to uncooked pork patties significantly delayed bacterial proliferation and extended the product shelf life beyond $14 \mathrm{~d}$ versus $7 \mathrm{~d}$ for the control.

The shelf life of fresh meat is usually limited by microbial spoilage. Fresh pork patties have a shelf life of around $7 \mathrm{~d}$ in refrigeration and aerobiosis depending on hygiene and preservation conditions (Tang et al., 2005). The inhibitory effect of VAL ethanol extract on microflora in uncooked pork patties may be attributed to the presence of polyphenolic compounds (quercetin, catechins, lignans, and phenolic acids) that enter the circulatory system, and are 
Table 5. Sensory evaluation ${ }^{1}$ results for uncooked pork patties mixed with VAL ethanol extract on the third day of storage

\begin{tabular}{llllll}
\hline & \multicolumn{5}{c}{ Treatments $^{2}$} \\
\cline { 2 - 6 } & \multicolumn{1}{c}{$\mathrm{C}$} & $\mathrm{V}$ & $\mathrm{T} 1$ & $\mathrm{~T} 2$ & $\mathrm{~T}$ \\
\hline Color & $4.52 \pm 1.13$ & $5.20 \pm 0.45$ & $4.30 \pm 1.10$ & $3.75 \pm 0.96$ & $4.50 \pm 1.66$ \\
Flavor & $4.70 \pm 0.84$ & $4.70 \pm 1.86$ & $4.50 \pm 0.22$ & $4.40 \pm 1.29$ & $5.00 \pm 1.58$ \\
Off-odor & $7.40 \pm 1.14^{\mathrm{A}}$ & $6.00 \pm 1.87^{\mathrm{B}}$ & $5.60 \pm 1.92^{\mathrm{C}}$ & $5.25 \pm 2.22^{\mathrm{C}}$ & $5.40 \pm 2.41^{\mathrm{C}}$ \\
Acceptability & $3.45 \pm 1.13$ & $5.43 \pm 1.66$ & $5.73 \pm 0.79$ & $5.70 \pm 1.14$ & $5.80 \pm 1.55$ \\
\hline
\end{tabular}

Values represent the mean of triplicate determinations.

VAL, Viscum album L.; SD, standard deviation.

${ }^{1}$ Scores were assigned based on a 9-point scale (color, flavor, and acceptability: $1=$ very objectionable, $9=$ very acceptable; odor: $1=$ low intensity, $9=$ very high intensity).

${ }^{2} \mathrm{C}$, uncooked pork patty without any added functional ingredients; $\mathrm{V}$, uncooked pork patty mixed with $0.02 \%$ ascorbic acid; T1, T2, and T3, fresh patties mixed with $0.1 \%, 0.5 \%$, and $1.0 \%$ VAL extract, respectively (dry base, $\mathrm{w} / \mathrm{w}$ ).

${ }^{A-C}$ Mean values \pm SD with different letters in the same row are significantly different $(\mathrm{p}<0.05)$.

distributed and retained in animal tissues (Raccach, 1984). These compounds interact with the cell membrane of microorganisms and cause leakage of cellular components, changes in fatty acid and phospholipid constituents, impaired energy metabolism, altered nutrient uptake and electron transport, and changes in genetic material synthesis (Nychas, 1995). Moreover, Fung et al. (1977) showed that these compounds could also interact with microorganism membrane proteins to produce structure deformation and disrupt functionality.

\section{Sensory evaluation of pork patties}

Sensory panel results for the VAL extract-treated pork patties are presented in Table 5. Comparison of the sensory evaluation data for the VAL extract-treated pork patties and control did not reveal any difference in color score, flavor score, or overall acceptability $(\mathrm{p}>0.05)$. However, odor scores of VAL extract-treated pork patties were lower than those of the control and $0.02 \%$ ascorbic acid-treated patties after $3 \mathrm{~d}$ of storage. This finding indicated that the VAL extract was able to improve the sensory qualities of uncooked patties, which could be attributed to the reduction of bacterial populations and lipid oxidation.

In conclusion, the results of the present investigation demonstrated that the VAL ethanol extract (containing 60.46 of total phenolics-mg of $\mathrm{CE} / \mathrm{g}$ and 36.38 of flavonoid-mg of QE/g, respectively) is a good source of antioxidants. In addition, in situ testing confirmed that $0.1 \%$ VAL ethanol extract is highly effective for maintain the quality of uncooked pork patties because this compound was able to inhibit lipid oxidation and consequently prevent odor development. The effects of this concentration of VAL extract were more potent than those of ascorbic acid. Data from this study strongly suggest that the VAL ethanol extract is a potential natural antioxidant source that can preserve the quality of meat and meat products.

\section{CONFLICT OF INTEREST}

We certify that there is no conflict of interest with any financial organization regarding the material discussed in the manuscript.

\section{ACKNOWLEDGMENTS}

This research was supported by a Daegu University Research Grant (20140576).

\section{REFERENCES}

Ahn, J., I. U. Grun, and L. N. Fernando. 2002. Antioxidant properties of natural plant extracts containing polyphenolic compounds in cooked ground beef. J. Food Sci. 67:1364-1369.

Ahn, J., I. U. Grün, and A. Mustapha. 2004. Antimicrobial and antioxidant activities of natural extracts in vitro and in ground beef. J. Food Prot. 67:148-155.

Bar-Sela, G. 2011. White-berry mistletoe (Viscum album L.) as complementary treatment in cancer: Does it help? Eur. J. Integr. Mad. 3:e55-e62.

Biswas, A. K., M. K. Chatli, and J. Sahoo. 2012. Antioxidant potential of curry (Murraya koenigii L.) and mint (Mentha spicata) leaf extracts and their effect on colour and oxidative stability of raw ground pork meat during refrigeration storage. Food Chem. 133:467-472.

Brand-Williams, W., M. E. Cuvelier, and C. Berset. 1995. Use of a free radical method to evaluate antioxidant activity. LWT-Food Sci. Technol. 28:25-30.

Brewer, M. S., H. Y. Lan, and F. K. McKeith. 1998. Consumer evaluation of pork appearance with differing physiological and packaging conditions. J. Muscle Foods 9:173-183.

Buxiang, S. and M. Fukuhara. 1997. Effects of co-administration of butylated hydroxytoluene, butylated hydroxyanisole and flavonoid on the activation of mutagens and drug-metabolizing enzymes in mice. Toxicology 122:61-72.

Carpenter, R., M. N. O'Grady, Y. C. O'Callaghan, N. M. O'Brien, and J. P. Kerry. 2007. Evaluation of the antioxidant potential of grape seed and bearberry extracts in raw and cooked pork. Meat Sci. 76:604-610.

Chen, H. Y. and G. C. Yen. 2007. Antioxidant activity and free radical-scavenging capacity of extracts from guava (Psidium guajava L.) leaves. Food Chem. 101:686-694.

Da Porto, C., S. Calligaris, E. Celotti, and M. C. Nicoli. 2000. Antiradical properties of commercial cognacs assessed by the 
DPPH test. J. Agric. Food Chem. 48:4241-4245.

Devatkal, S. K., K. Narsaiah, and A. Borah. 2010. Anti-oxidant effect of extracts of kinnow rind, pomegranate rind and seed powders in cooked goat meat patties. Meat Sci. 85:155-159.

Draper, H. H., E. J. Squires, H. Mahmoodi, J. Wu, S. Agarwal, and M. Hadley. 1993. A comparative evaluation of thiobarbituric acid methods for the determination of malondialdehyde in biological materials. Free Radic. Biol. Med. 15:353-363.

Ehleringer, J. R. and J. D. Marshall. 1995. Water relations. In: Parasitic plants (Eds. M. C. Press and J. Graves). Chapman and Hall, London, UK. 125-214.

Fernández, T., M. L. Wagner, B. G. Varela, R. A. Ricco, S. E. Hajos, A. A. Gurni, and E. Alvarez. 1998. Study of an Argentine Mistletoe, the hemiparasite Ligaria cuneifolia (R. et P.) Tiegh. (Loranthaceae). J. Ethnopharmacol. 62:25-34.

Franz, H., P. Ziska, and A. Kindt. 1981. Isolation and properties of three lectins from mistletoe (Viscum album L.). Biochem. J. 195:481-484

Fung, D. Y. C., S. Taylor, and J. Kahan. 1997. Effect of butylated hydroxyanisole (BHA) and buthylated hydroxytoluene (BHT) on growth and aflatoxin production of Aspergillus flavus. J. Food Saf. 1:39-51.

Ganhão, R., M. Estévez, and D. Morcuende. 2011. Suitability of the TBA method for assessing lipid oxidation in a meat system with added phenolic-rich materials. Food Chem. 126:772-778.

Halliwell, B. 1996. Ascorbic acid in the prevention and treatment of cancer. Altern. Med. Rev. 3:174-186.

Halliwell, B., J. M. C. Gutteridge, and O. I. Aruoma. 1987. The deoxyribose method: A simple "test-tube" assay for determination of rate constants for reactions of hydroxyl radicals. Anal. Biochem. 165:215-219.

Jung, M. L., S. Baudino, G. Ribereau-Gayon, and J. P. Beck. 1990. Characterization of cytotoxic proteins from mistletoe (Viscum album L.). Cancer Lett. 51:103-108.

Juntachote, T., E. Berghofer, S. Siebenhandl, and F. Bauer. 2007. Antioxidative effect of added dried Holy basil and its ethanolic extracts on susceptibility of cooked ground pork to lipid oxidation. Food Chem. 100:129-135.

Khalil, A. H. and E. H. Mansour. 1998. Control of lipid oxidation in cooked and uncooked refrigerated carp fillets by antioxidant and packaging combinations. J. Agric. Food Chem. 46:11581162.

Khwaja, T. A., J. C. Varven, S. Pentecost, and H. Pande. 1980. Isolation of biologically active alkaloids from Korean mistletoe Visum album, colouratum. Experientia 36:599-600.

Kim, S. J., A. R. Cho, and J. J. Han. 2013. Antioxidant and antimicrobial activities of leafy green vegetable extracts and their applications to meat product preservation. Food Control 29:112-120.

Liu, F., V. E. C. Ooi, and S. T. Chang. 1997. Free radical scavenging activities of mushroom polysaccharide extracts. Life Sci. 60:763-771.

Lopes, G. K., H. M. Schulman, and M. Hermes-Lima. 1999. Polyphenol tannic acid inhibits hydroxyl radical formation from Fenton reaction by complexing ferrous ions. Biochim. Biophys. Acta 1472:142-152.

Mannel, D. N., H. Becker, A. Gundt, A. Kist, and H. Franz. 1991. Induction of tumor necrosis factor expression by a lectin from
Viscum album. Cancer Immunol. Immunother. 33:177-182.

Mason, L. M., S. A. Hogan, A. Lynch, K. O’Sullivan, P. G. Lawlor, and J. P. Kerry. 2005. Effects of restricted feeding and antioxidant supplementation on pig performance and quality characteristics of longissimus dorsi muscle from Landrace and Duroc pigs. Meat Sci. 70:307-317.

Mates, J. M. and F. M. Sanchez-Jimenez. 2000. Role of reactive oxygen species in apoptosis: Implications for cancer therapy. Int. J. Biochem. Cell Biol. 32:157-170.

McBride, N. T. M., S. A. Hogan, and J. P. Kerry. 2007. Comparative addition of rosemary extract and additives on sensory and antioxidant properties of retail packaged beef. Int. J. Food Sci. Technol. 42:1201-1207.

McCarthy, T. L., J. P. Kerry, J. F. Kerry, P. B. Lynch, and D. J. Buckley. 2001a. Evaluation of the antioxidant potential of natural food/plant extracts on compared with synthetic antixodants and vitamin $\mathrm{E}$ in raw and cooked pork patties. Meat Sci. 58:45-52.

McCarthy, T. L., J. P. Kerry, J. F. Kerry, P. B. Lynch, and D. J. Buckley. 2001b. Assessment of the antioxidant potential of natural food and plant extracts in fresh and previously frozen pork patties. Meat Sci. 57:177-184.

Meda, A., C. E. Lamien, M. Romito, J. Millogo, and O. G. Nacoulma. 2005. Determination of the total phenolic, flavonoid and proline contents in Burkina Fasan honey, as well as their radical scavenging activity. Food Chem. 91:571-577.

Mueller, E. A. and F. A. Anderer. 1990. Viscum album oligosaccharide activating human natural cytotoxicity is an interferon $\gamma$ inducer. Cancer Immunol. Immunother. 32:221227.

Nychas, G. J. E. 1995. Natural antimicrobials from plants. New methods of food preservation (Ed. G. W. Gould), Blackie Academic Professional, London, UK. pp. 58-89.

Oliveira, T. L. C., S. M. Carvalho, R. Araújo Soares, M. A. Andrade, M. Graças Cardoso, and E. M. Ramos. 2012. Antioxidant effects of Satureja montata L. essential oil on TBARS and color of mortadella-type sausages formulated with different levels of sodium nitrite. LWT - Food Sci. Technol. 45:204-212.

Paganga, G., N. Miller, and C. A. Rice-Evans. 1999. The polyphenolic content of fruit and vegetables and their antioxidant activities. What does a serving constitute? Free Radic. Res. 30:153-162.

Raccach, M. 1984. The antimicrobial activity of phenolic antioxidants in foods: A review. J. Food Saf. 6:141-170.

Renerre, M. 2000. Review - biochemical basis of fresh meat color. In Proceedings of the 45th international congress of meat science and technology, Yokohama, Japan. pp. 344-352.

Romagnoli, S., R. Ugolini, F. Fogolari, G. Schaller, K. Urech, M. Giannattasio, L. Ragona, and H. Molinari. 2000. NMR structural determination of viscotoxin A3 from Viscum album L. Biochem. J. 350:569-577.

Singleton, V. L. and J. R. Rossi. 1965. Colorimetry of total phenolics with phosphomolybdic-phosphotungstic acid. Am. J. Enol. Vitic. 16:144-158.

Tang, S. Z., S. Y. Ou, X. S. Huang, W. Li, J. P. Kerry, and D. J. Buckley. 2005. Effects of added tea catechins on colour stability and lipid oxidation in minced beef patties held under 
aerobic and modified atmospheric packaging conditions. J. Varela, B. G., T. Fernández, R. A. Ricco, P. C. Zolezzi, S. E. Hajos, Food Eng. 77:248-253.

Tarladgis, B. G., B. M. Watts, and M. T. Younathan. 1960. A distillation method for the quantitative determination of malondialdehyde in rancid foods. J. Am. Oil Chem. Soc. 37: 44-48.

Vani, T., M. Rajani, S. Sarkar, and C. J. Shishoo. 1997. Antioxidant properties of the ayurvedic formulation triphala and its constituents. Int. J. Pharmacogn. 35:313-317.

A. A. Gurni, E. Alvarez, and M. L. Wagner. 2004. Phoradendron liga (Gill. ex H. et A.) Eichl. (Viscaceae) used in folk medicine: anatomical, phytochemical, and immunochemical studies. J. Ethnopharmacol. 94:109-116.

Zolezzi, P. C., T. Fernández, P. Aulicino, V. Cavaliere, S. Greczanik, E. C. Lopes, M. Wagner, R. Ricco, A. Gurni, S. Hajos, and E. Álvarez. 2005. Ligaria cuneifolia flavonoid fractions modulate cell growth of normal lymphocytes and tumor cells as well as multidrug resistant cells. Immunobiology 209:737-749. 